\title{
LUDICIDADE E LITERATURA: O DESPERTAR DA FORMAÇÃO DE LEITORES NA INFÂNCIA
}

\author{
Edenar Souza Monteiro ${ }^{1}$ \\ https://orcid.org/0000-0002-9666-7920 \\ Fabiana Flavia de Magalhães Nascimento² \\ https://orcid.org/0000-0003-4170-6643
}

RESUMO: Com o objetivo de contribuir com as discussões relativas à contação de histórias para crianças, abordamos neste artigo algumas das questões que revelam esta prática como um recurso metodológico mediador da aprendizagem e do desenvolvimento das crianças em creches e pré-escolas. Trata-se de uma pesquisa de cunho qualitativo e método bibliográfico que teve como suporte teórico Zilberman (2003); Rojas (2007); Kramer, 2001; Abramovich, (1997); Ariès (1986) entre outros. Os resultados apontaram que a contação de história pode ser considerada como um instrumento prazeroso com efeitos significativos para o desenvolvimento e aprendizagem das crianças na Educação Infantil e, apontaram também que é relevante que o professor crie ricas e variadas situações de interação e comunicação por meio da ludicidade e da narrativa para que a contação de história se torne ator principal no fazer pedagógico com crianças pequenas.

PALAVRAS-CHAVE: Educação Infantil, Literatura, Ludicidade.

\section{PLAYFULNESS AND LITERATURE: THE AWAKENING OF READER FORMATION IN CHILDREN}

ABSTRACT: In order to contribute to the discussions related to storytelling for children, we discuss in this article some of the issues that reveal this practice as a methodological resource that mediates the learning and development of children in day care centers and preschools. This is a qualitative research and bibliographic method that had as theoretical support Zilberman (2003); Rojas (2007); Kramer, 2001; Abramovich (1997); Ariès (1986) among others. The results pointed out that storytelling can be considered as a pleasurable instrument with significant effects on the development and learning

\footnotetext{
${ }^{1}$ Doutora em Educação pela UFMT, Docente do Programa de Mestrado em Ensino (PPGen) Universidade de Cuiabá, Cuiabá, Mato grosso, Brasil. edenar.m@gmail.com

${ }^{2}$ Graduada em Pedagogia pela UFMT, Mestranda do Programa de Mestrado em Ensino (PPGen) Universidade de Cuiabá, Cuiabá, Mato grosso, Brasil.f.flavianas@gmail.com.
} 
of children in early childhood education. playfulness and narrative so that storytelling becomes the main actor in pedagogical practice with young children.

KEYWORDS: Early Childhood Education, Literature, Ludicity.

\section{JUEGOS Y LITERATURA: EL DESPERTAR DE LA FORMACIÓN DE LECTORES EN NIÑOS}

RESUMEN: Para contribuir a las discusiones relacionadas con la narración de cuentos para niños, discutimos en este artículo algunos de los problemas que revelan esta práctica como un recurso metodológico que media el aprendizaje y el desarrollo de los niños en guarderías y centros preescolares. Este es un método cualitativo de investigación y bibliografía que tuvo como soporte teórico a Zilberman (2003); Rojas (2007); Kramer, 2001; Abramovich (1997); Ariès (1986) entre otros. Los resultados señalaron que la narración de cuentos se puede considerar como un instrumento placentero con efectos significativos en el desarrollo y el aprendizaje de los niños en el jardín de infantes y también señaló que es relevante para el maestro crear situaciones ricas y variadas de interacción y comunicación a través de alegría y narrativa para que la narración se convierta en el actor principal en la práctica pedagógica con niños pequeños.

PALABRAS CLAVE: Educación de la primera infancia, literatura, ludicidad.

\section{Introdução}

Atualmente as discussões sobre a educação das crianças de 0 a 5 anos, vem apontando que a área da Educação infantil vive um intenso processo de revisão de concepções, seleção e fortalecimento de práticas pedagógicas mediadoras da aprendizagem promovendo o desenvolvimento das crianças atendidas em creches e pré-escolas. Principalmente, a discussão sobre como orientar o trabalho pedagógico junto às crianças tem sido tema de estudos e reflexões nos cursos de formação de profissionais desta etapa de ensino. Como tais, temos um lugar garantido e privilegiado, contudo com grandes responsabilidades, o que nos leva a refletir sobre o nosso papel e influência no desenvolvimento e aprendizagens dos pequenos.

O primeiro passo consiste em compreender como e mediante quais situações ocorrem estes processos? Que relações possuem? Qual perspectiva teórico-metodológica possibilita compreender e orientar a melhor forma de 
educação e cuidado para as crianças da Educação infantil? Neste viés o estudo buscou referências na matriz sócio construtivista, a partir de Vygotsky (1991) sobre os processos de desenvolvimento e aprendizagem, pensamento e linguagem, o qual acredita que o desenvolvimento é um processo de apropriação ativa do conhecimento que se dá mediante interação social. Pressupõe-se que desenvolvimento e aprendizagem são processos que se influenciam reciprocamente.

Vygotsky (1991) aponta que o homem é um ser eminentemente social e considera que a elaboração da consciência ocorre a partir de uma crescente apropriação dos modos de ação culturalmente construídos, no qual sua apropriação ocorre por meio do contato social, em que o sujeito realiza um processo de internalização. Nessa questão, destaca a linguagem como caminho pelo qual a consciência humana se forma, inclusive atribui ao educador o papel de mediador, por acreditar que não é possível desenvolver conhecimento de forma individualista compreendendo que sem interação não há aprendizagem.

Partindo desse pressuposto, aprendizagem é um processo de passagem do nível de desenvolvimento real, aquilo que a criança já sabe, para o nível de desenvolvimento potencial, aquilo que é capaz de aprender com o auxílio do mediador: adultos e crianças. Chega-se a uma concepção de criança como ser social e histórico, o que significa que seu desenvolvimento se dá entre outros seres humanos, em um espaço e tempo determinado e seu conhecimento é fruto de uma construção pessoal, resultado de um processo interno de pensamento que se dá a partir do desenvolvimento da fala. (VYGOTSKY, 1991)

O trabalho com a linguagem constitui um dos eixos básicos na Educação, devido sua importância na formação do sujeito, na construção de conhecimentos e no desenvolvimento do pensamento. Tendo como finalidade a formação integral da criança. Cabe-nos a responsabilidade de proporcionar experiências significativas que promovam o desenvolvimento e aprendizagens em situações de interação que permitam aos pequenos a leitura/releitura, significação e ressignificação da realidade.

A partir desses pressupostos, tornam-se necessário propiciar momentos que favoreçam a expressão da linguagem e da imitação, formas pelas quais a criança representa e se comunica com tudo que a cerca. Portanto, é preciso criar situações para que a contação de história se realize, pois pela prática de contar história, como atividade lúdica, é possível mediar o desenvolvimento e conhecimento das crianças.

Com base nesses fundamentos, este estudo busca contribuir com as reflexões acerca de narrativas infantis onde, a partir de referenciais teóricos 
pesquisados temos o objetivo de evidenciar a importância de contar história para as crianças.

Este artigo também permite a todos que se interessam pela educação de crianças refletir, compreender e levantar discussões acerca da prática pedagógica envolvendo a Literatura infantil e a contação de histórias, fazendo desta um excelente recurso para o desenvolvimento da linguagem, da imaginação e do senso crítico na criança.

\section{A Literatura e a Educação Infantil}

A Literatura sempre teve um caráter utilitário e moralista, como veículo de transmissão de valores. As obras literárias veiculavam ideologias procurando apresentar à sociedade um modelo de vida segundo os interesses da classe dominante. Procurava-se, através das histórias, apresentar um modelo de vida segundo os interesses dessa nova classe emergente. Sem dúvida, um modelo que facilitasse à burguesia a sua permanência no poder. Somente com a evolução do capitalismo e crescente urbanização, surgem a partir de 1970, escritores que produzem novos estilos e as obras ganham uma compreensão estética, abandonado o caráter moralista da literatura.

Foi no final do século XVII que lentamente emerge o sentimento sobre a infância, porém, somente mais recentemente passa a ser considerada como etapa importante na vida do ser humano, no entanto, ainda assim a criança tinha certas restrições de acesso à literatura. (LEARDINI, 2006)

Rojas (200, p.36), aponta que "a socialização da criança, assim como as transmissões dos valores e dos conhecimentos advinha da convivência com o adulto que ganhava certa independência, era logo misturada aos adultos, partilhava de seus trabalhos e jogos, garantindo assim sua educação". Assim, a infância desconsiderada nas suas especificidades, fazia da criança um adulto em miniatura. Nesta linha de pensamento, ARIÈS (1986) defende que o conceito de infância, no sentido de oposto de adulto, é uma construção que se materializou com a modernidade, surgindo no final do século XVII, nas camadas superiores da sociedade e se sedimentando no século XVIII.

Assim Zilberman (2003, p. 28) afirma que a "valorização da infância como etapa diferenciada e importante aconteceu a partir da ascensão da família burguesa, no século XVIII". Conforme reitera Ariès (1986, p. 35), "com o novo status assumido pela família, a criança passou a ser o centro da atenção e merecer prioridade, tanto no que se refere à educação intelectual quanto aos cuidados", higiene e afeição. Móveis, brinquedos, roupas e diversos ar- 
tefatos, produtos e serviços foram criados com o objetivo de atender a esse novo sujeito que passa a ser reconhecido como portador de peculiaridades que necessitavam de um atendimento especial,

Neste contexto de atendimento as especificidades da criança, a partir do capitalismo, que vê este pequeno como consumidor, e essa relação entre a mercantilização e a infância faz com que as relações, a inserção e o papel social da criança na sociedade se configurem de uma outra maneira. (KRAMER, 2001)

$\mathrm{Se}$, na sociedade feudal, a criança exercia um papel produtivo direto (de adulto), na sociedade burguesa ela passa a ser alguém que precisa ser cuidada, escolarizada e preparada para uma atuação futura. (ARIÈS, 1986)

Quanto a Literatura Infantil, ela emerge no contexto das transformações sociais e culturais, tendo por objetivo aproximar a criança de um mundo repleto de atitudes e valores que regulam a vida adulta, por meio da adaptação de contos de fada, na tentativa de preparar a criança para enfrentar a realidade. Nessa perspectiva Zilbermann (2003) evidencia que a Literatura Infantil surgiu em meio essas transformações e marcou a civilização europeia moderna.

Os textos e livros produzidos para as crianças evidenciavam os valores do mundo burguês com a finalidade de promover padrões comportamentais, garantir a formação das crianças para as demandas postas pela sociedade, preparando-as para ocupar o lugar dos pais no trabalho e na sociedade.

Isto demonstra que os valores burgueses têm preocupação com a Literatura dirigida à criança. Como nos conta Carvalho (1989), a ruptura da transição oral, na sociedade burguesa, dissolveu os grupos que, indiscriminadamente, se reuniam, nas sociedades feudais e patriarcais, para ouvir os contadores de histórias, assim estabelece o hábito de ler, individualmente ou para grupos distintos: para adultos e para crianças, levando-se em consideração a adequação dos textos para crianças.

Inicia a diferenciação e a especificidade da Literatura Infantil. A família assume o lar e suas crianças, abolindo o hábito da sociabilidade, criando sua privacidade e desenvolvendo a afetividade, situação em que a criança passou a encontrar o verdadeiro clima da infância. No entanto, este privilégio foi dado apenas às crianças burguesas, na classe popular as crianças continuavam desprotegidas e usadas para o trabalho.

Segundo Oliveira (2008), o século XX se apresenta com um pensamento de maior preocupação em relação à criança. Vale ressaltar que ao longo deste século, a educação das crianças foi caracterizada pela filantropia, pela assistência social, pela superação de carências, pelo cuidar e educar.

Um marco importante na difusão da Literatura infantil foi a expansão 
da tipografia no século XVIII, tornando mais efetiva a produção de livros e a proliferação de gêneros literários. A Literatura infantil utilizando-se da língua escrita torna imprescindível a capacidade de leitura das crianças, passando para a escola a responsabilidade de habilitá-las para o consumo de livros confeccionados cada vez mais em escala crescente.

Nesse momento, a escola desempenha seu papel de formadora de leitores, realçando sua condição de mediadora, assumindo a responsabilidade pela ligação entre a Literatura e a criança.

A literatura infantil e escola, juntas, se unem para organizar as informações necessárias ao desenvolvimento intelectual desse novo ser: a criança. Até o século XIX, as obras literárias para as crianças ainda eram marcadas pela finalidade moralizante e doutrinária do século anterior. Na atualidade podemos observar o crescimento qualitativo dos livros de literatura infantil com uma diversidade de textos que ajudam a prática educativa do professor, sendo instrumento fundamental para apoiar a atividade de contação de histórias.

No Brasil, a Literatura Infantil surge no século XIX demonstrando seu percurso histórico e cultural, de caráter conservador, que se define como cívico-pedagógico. As primeiras produções impressas partiram da adaptação e tradução de várias obras, em sua maioria, clássicos europeus, porém ainda não genuinamente infantis, faltava algo que as caracterizasse e identificasse com o pequeno leitor.

Neste contexto, Zilberman e Lajolo (1986), destacam que Olavo Bilac em 1888, escreveu poesias infantis e Contos Pátrios, onde promovia a exaltação à Pátria contribuindo para o projeto nacionalista brasileiro. Este autor se preocupava em escrever principalmente sobre o civismo, o que ficava muito presente em seus feitos como profissional da educação que era.

Também José de Alencar, que embora fosse mais ameno em suas produções, não deixava passar despercebida sua preocupação com a moral e os bons costumes. No século XIX, a Literatura para as crianças ainda era marcada pela finalidade moralizante e doutrinária, pela preocupação em excesso com a norma culta da língua.

Havia na Literatura Infantil preocupação com o projeto de desenvolvimento nacional que se manifestava por meio da exaltação da natureza brasileira, pela diversidade e grandeza regional e nacional, a exaltação dos vultos e dos episódios da história do Brasil. (ZILBERMAN e LAJOLO, 1986)

A Literatura Infantil passou a ser considerada gênero durante o século XVII, época de muitas mudanças sociais, principalmente no âmbito artístico. De acordo com Oliveira e Spindola (2008) diversos autores sustentam a tese 
de que a designação 'infantil', para a literatura destinada às crianças, possa conferir-lhe um valor menor, sem importância e sem qualidade, o que não é apropriado, pois a Literatura Infantil, atualmente, tem aumentado o compromisso dos seus autores, impondo-lhes maior responsabilidade e melhor fundamentação na produção literária.

Vários escritores nacionais foram surgindo a partir das traduções da literatura estrangeira que somadas às histórias folclóricas nacionais criadas pelos índios e pelos escravos, deram corpo a Literatura Infantil brasileira. Dentre os tradutores/escritores brasileiros, temos como maior representante Monteiro Lobato que graças ao conjunto da sua obra literária, voltada para crianças, jovens e adultos revolucionou a indústria editorial no País e fez com que a Literatura Infantil brasileira ganhasse notoriedade e solidez.

A Literatura Infantil contemporânea diferentemente da Literatura de séculos passados, em que o objetivo central era estimular a obediência, o rigor dos costumes e normas impostas, considerando a criança um ser moldado pela sociedade, a nova Literatura infantil, a partir de Monteiro Lobato muda sua configuração a fim de instigar na criança um comportamento curioso e irreverente.

Adota-se, a partir de então, uma perspectiva realista na criação das obras para a criança. Os autores assumem que a criança já não é mais alguém passivo como a de outras épocas. O autor, ao escrever para ela, quer mostrar-Ihe os problemas do cotidiano e ampliar sua visão de mundo.

A história da Literatura permite que se compreenda que, ao longo dos séculos, a criança e o livro assumiram diferentes significados. A Literatura Infantil está no centro do processo de transformações que vem passando a sociedade e têm vínculos estreitos com a escola, o que, levou Zilberman (2003) a afirmar que a literatura infantil é primeiramente um problema pedagógico, e não literário. Apesar de suas vinculações pedagógicas a literatura infantil pode oferecer à criança, desde que devidamente cuidada, a percepção de aspectos literários e artísticos que desenvolvem a sensibilidade do leitor infantil e sua imaginação.

\section{A Contação de História e a Educação Infantil}

Na Educação Infantil, a brincadeira é a principal forma de aprendizagem e socialização da criança. O brincar permeia todas as suas relações com o mundo, pois é resultado das relações culturais, sociais e do desenvolvimento de valores e atitudes. A garantia da brincadeira é a garantia de possibilidades 
de um processo educativo numa perspectiva criativa e consciente. Nas situações lúdicas as crianças aprendem a resolver conflitos e estabelecer relações, já que essas situações possibilitam o exercício da escolha, contribuindo para o entendimento da individualidade e do processo de construção da autonomia.

A literatura infantil possui amplas e importantes dimensões. Ela proporciona à criança um desenvolvimento emocional, social e cognitivo indiscutível. Segundo Abramovich (1997, p. 17), "quando as crianças ouvem histórias, passam a visualizar de forma mais clara, sentimentos que têm em relação ao mundo". As histórias trabalham problemas existenciais típicos da infância, "como medos, sentimentos de inveja e de carinho, curiosidade, dor, perda, além de ensinarem infinitos assuntos".

Bakhtin (1992, p. 112), aponta que "quando a criança ouve ou lê uma história e é capaz de comentar, indagar, duvidar ou discutir sobre ela, realiza uma interação verbal, que neste caso, vem ao encontro das noções de linguagem". Para esse autor, "o confronto de ideias, de pensamentos em relação aos textos, tem sempre um caráter coletivo, social". O autor reforça ainda que "o conhecimento é adquirido na interlocução, o qual evolui por meio do confronto, da contrariedade. Assim, a linguagem é constitutiva, isto é, o sujeito constrói o seu pensamento, a partir do pensamento do outro, portanto, uma linguagem dialógica". ( $p, 113)$

Desse modo, em seus estudos, Vygotsky (1991) sintetizou uma perspectiva de homem enquanto ser biológico, social e histórico. Ou seja, para este teórico, o funcionamento psicológico fundamenta-se nas relações sociais entre o individuo e o mundo, as quais se desenvolvem num processo histórico.

De acordo com Horn (2004), na perspectiva sócio-histórica de desenvolvimento, Vygotsky relaciona afetividade, linguagem e cognição com as práticas sociais, constituindo o meio social fator preponderante na construção e no desenvolvimento dos indivíduos, sendo este produtor de conhecimento numa relação dialética com o mundo.

Estudiosos afirmam que na Educação Infantil, como espaço de socialização, a interação social com diferentes atores estimula o potencial de socialização e desempenha um importante papel no processo de desenvolvimento psíquico da criança.

Segundo Rojas (2007) a aquisição da cultura decorre do processo de interação da criança com as vivencias sociais do seu meio. Acrescenta que a emoção é um dos elementos constituintes da atividade mediadora de ações e operações humanas, pois a ação do indivíduo se guia por sinais, vivências, marcas emocionais de acontecimentos e símbolos. Ainda este autor observa 
que na criança, linguagem e percepção estão intimamente ligados e, que a percepção dos objetos reais, um dos aspectos especiais da percepção humana, é parte de um sistema dinâmico de comportamento onde as relações entre as transformações dos processos perceptivos e as que ocorrem em outras atividades são de fundamental importância. Segundo a autora, com base nesse pensamento Vygotsky (1994) chamou esse fenômeno de: ver o mundo com sentido e significado.

Entende-se que desta forma, o processo de formação de pensamento é, portanto, despertado e acentuado pela vida social e pela constante comunicação que se estabelece entre crianças e adultos, a qual permite a assimilação da experiência de muitas gerações. Ou seja, o processo de desenvolvimento intelectual da criança intervém da linguagem por intermédio de sua interação com outras crianças e adultos.

Na perspectiva sociointeracionista, o desenvolvimento humano deve ser compreendido na sua correlação entre as dimensões motora, afetiva e cognitiva. A dimensão motora do desenvolvimento humano tem como fundamento a questão do movimento. Os bebês encontram sob o domínio do movimento reflexo, impulsivo e incoordenado. À medida que a criança cresce observa-se o surgimento dos primeiros atos voluntários, que gradativamente evoluem para manifestações intencionais.

A partir dos três anos observa-se a exuberância motora das crianças com movimentos cada vez mais eficazes. Nesse período, apesar da emergência da linguagem inibir a ação motora, em contrapartida a criança apresenta aumento da concentração e, por conseguinte, a manifestação do movimento ideomotor, ou seja, a capacidade do planejamento mental do movimento.

Na dimensão afetiva do desenvolvimento, os bebês se encontram em um estado de fusão entre o eu e o outro, ou indiferenciação. O sorriso e choro constituem o diálogo tônico da criança com o outro, com o mundo; é o primeiro esboço do seu psiquismo. Já dos 12 meses aos três anos inicia-se a constituição da consciência corporal, ou seja, da individualização e diferenciação das partes do corpo. A criança mantém diálogo consigo mesma e com um interlocutor imaginário.

Segundo a Proposta Pedagógica para a Educação Infantil do Município de Cuiabá (2009) a partir destas dimensões têm-se os indicadores adotados para orientar a dinâmica do trabalho pedagógico com crianças pequenas, destacando como principais: a representação mental do movimento, a diferenciação e, o pensamento representacional e simbólico.

Ludicidade e narrativa, entendidos como facilitadores do desenvolvi- 
mento infantil que devem permear toda ação educativa realizada na Educação Infantil. Segundo a Proposta (2009) a expressão lúdica caracteriza a qualidade do jogo, em seu caráter livre, não-sério, não-produtivo, um processo prazeroso por natureza que deve ser tomado como a principal dimensão do trabalho com as crianças pequenas.

A certa altura do seu desenvolvimento, a criança amplia os limites de sua compreensão, integrando símbolos socialmente elaborados (valores, crenças sociais, o conhecimento acumulado da cultura e os conceitos científicos) ao seu próprio conhecimento. Esse processo dialético entre a criança e a sociedade tem na linguagem um dos signos mais importantes do desenvolvimento infantil.

Portanto, as atividades lúdicas propiciam à criança a possibilidade de conviver com diferentes sentimentos interiores, elas demonstram através das brincadeiras como vê e constrói o mundo, como gostaria que ele fosse e quais as suas preocupações e que problemas a estão atormentando, ou seja, expressam na brincadeira o que tem dificuldade de expressar com palavras.

Entende-se que a criança estrutura o mundo a partir da ludicidade, que fundamenta suas ações, emoções, seu pensamento imaginativo e criativo, possibilitando a compreensão e representação de tudo que a cerca e instiga.

Segundo a Proposta Pedagógica do Município de Cuiabá, as narrativas envolvem memória, dimensão temporal, capacidade de compreender e capacidade para organizá-los em uma cadeia lógica. Elas podem ser vistas como veículo e material de construção sociocognitiva da realidade e de significados, veículo que provoca campos de experiências intersubjetivas que promovem compreensão das formas simbólicas, ao mesmo tempo em que é um instrumento de organização da experiência social e de transformação desta em discurso.

O Referencial Curricular Nacional da Educação Infantil (1998) cita que a narrativa pode e deve ser a porta de entrada de toda criança para os mundos criados pela literatura. A criança aprende a narrar por meio de jogos de contar e de histórias, propondo que as instituições de Educação Infantil resgatem o repertório de histórias que as crianças ouvem em casa e nos ambientes que frequentam, uma vez que essas histórias se constituem em rica fonte de informação sobre as diversas formas culturais de lidar com as emoções e com as questões éticas, contribuindo na construção da subjetividade e da sensibilidade das crianças.

Podemos no momento de contar história e ler para as crianças apresentá-las a outros mundos, outras culturas, outros valores e comportamentos; porém, cientes que estes não são os únicos objetivos. Não esquecer o verda- 
deiro sentido, ou seja, contar história pelo prazer que emana, pela imaginação que flui, pela curiosidade que desperta.

A narrativa chega cedo a vida da criança, desde seus primeiros dias de vida, quando a mãe conversa, canta para o filho durante a gestação. Em seguida, chega através dos acalantos que mais tarde dão lugar às cantigas de roda, às narrativas curtas sobre crianças, animais ou natureza.

As crianças que ainda não sabem ler gostam de ouvir sempre a mesma história, que se revela nova cada vez que é contada. Na verdade, elas estão sendo memorizadas, pois cada vez que ouvem fixam-na mais nitidamente. Pode parecer enfadonho para o adulto, mas é uma necessidade para a criança, pelo prazer de reconhecê-la, de apreendê-la em seus detalhes, a sequência dos fatos, de antecipar as emoções que teve da primeira vez.

Outro fato relevante é o vínculo afetivo que se estabelece entre o contador das histórias e a criança. Ao contar e ouvir uma história pode-se criar um clima afetivo e de aproximação entre as pessoas, que compartilham dessa experiência gostosa de descoberta do mundo das histórias da Literatura.

À medida que cresce a criança já é capaz de escolher a história que quer ouvir, ou a parte da história que mais Ihe agrada e passam a se interessar pelas histórias dos livros, como os contos de fadas ou contos maravilhosos, e outros. Tem-se nessa perspectiva, a possibilidade de envolver o real e o imaginário, pois de acordo com Sisto (2009) os livros aumentam muito o prazer de imaginar coisas e é a partir de histórias simples que a criança começa a reconhecer e interpretar sua experiência da vida real.

Conforme Abramovich (1997) é importante contar histórias mesmo para as crianças que já sabem ler, pois criança ao saber ler estabelece uma relação diferente, mas não deixa de ser prazer ouvi-las. Quando as crianças maiores ouvem as histórias, aprimoram a sua capacidade de imaginação, já que ouvi-las pode estimular o pensar, o desenhar, o escrever, o criar, o recriar.

Garantir a riqueza da vivência narrativa desde os primeiros anos de vida da criança contribui para o desenvolvimento do seu pensamento lógico e de sua imaginação, que de acordo com Vygotsky (1991) a imaginação é um momento totalmente necessário, inseparável do pensamento realista. Neste sentido, o teórico enfoca que na imaginação, a direção da consciência tende a se afastar da realidade. Esse distanciamento da realidade através de uma história, por exemplo, é essencial para uma penetração mais profunda na própria realidade. A criança vive num mundo de faz de conta, transformando o estático em dinâmico, buscando através de o imaginário descobrir e entender o mundo que a cerca. 
Importantes emoções são desencadeadas ouvindo histórias, como a tristeza, a raiva, a irritação, o bem-estar, o medo, a alegria, a insegurança, vivendo profundamente tudo o que as narrativas provocam em quem as ouve, com toda a amplitude, significância e verdade que elas podem despertar nos pequenos ouvintes e através das histórias se aprende a lidar com cada uma delas.

Enfim, as histórias propiciam à criança o desenvolvimento da imaginação e da interpretação da realidade. A partir do lúdico e do faz de conta, a criança torna-se autora de seus papéis, escolhendo, julgando, elaborando as ações dos personagens, emitindo valores sem a intervenção direta do adulto, solucionando problemas de forma livre das pressões situacionais da realidade imediata. Dessa forma, contar história se constitui alimento precioso para formação das crianças.

Rojas (2007, p.29), acrescenta que "a emoção como fator determinante no processo de mediação no ensino-aprendizagem. É evidente que essa aquisição passa necessariamente pela escola. Isto significa que o professor precisa lançar novo "olhar" sobre suas ações e, sobretudo, sobre o mundo que está a sua volta". Esse olhar pode proporcionar novas interpretações, ao analisar as ações docentes, revelando novo educador, diante das capacidades intelectuais, afetivas e emocionais do aprendiz.

Na educação de crianças, "a ação intencional do educador deve estar voltada para os objetivos pedagógicos do brincar, uma vez que, do ponto de vista do desenvolvimento, a criação de uma situação imaginária pode ser considerada meio para desenvolver o pensamento abstrato", é preciso também levar em conta cada faixa de idade, com suas especificidades. O brincar não é uma atividade de passa tempo ou perda de tempo, sinônimo de bagunça, brigas e de falta de domínio do educador. (VYGOTSKY, 1994, p.38)

O aspecto lúdico não está presente somente nas brincadeiras, mas no jeito de a criança pensar e representar o que conhece, fazendo diversas conexões com o que está vivendo e aprendendo sobre o mundo, os objetos, as pessoas e suas relações com o outro.

Contar história é um ritual que acontece há muitos anos, em lugares e culturas diferentes. Muitos mitos foram criados para fortalecer caçadores e guerreiros. Os povos antigos contavam história para aclamar as pessoas de suas dores, suas perdas e angústias.

Os contos falam de sentimentos. Os contos de fadas são as únicas histórias que de maneira simples e simbólica falam das perdas, da fome, da morte, do medo, do abandono, da violência... Eles têm suas bases nas camadas 
do inconsciente coletivo, em sentimentos comuns a toda a humanidade, por isso encontramos histórias bastante parecidas em diversas culturas pelo globo e em épocas diversas. Os contos de fadas possuem um fundo arquetípico, sentimentos complexos organizados de um modo fácil de entender especialmente pelas crianças, mostram que é natural ter pensamentos destrutivos e maus, que não se é essencialmente construtivo e bom e que é preciso ordenar os sentimentos e as tendências contraditórias.

Ter acesso à boa Literatura é dispor de uma informação cultural que alimenta a imaginação e desperta o prazer pela leitura. A intenção de fazer com que as crianças, desde cedo, apreciem o momento de sentar para ouvir histórias exige que o professor, como leitor, preocupe-se em lê-la com interesse, criando um ambiente agradável e convidativo à escuta atenta, mobilizando a expectativa das crianças, permitindo que elas olhem o texto e as ilustrações enquanto a história é lida.

Contar e ouvir histórias além de ser um acontecimento prazeroso, desperta na criança o interesse e a gostar ainda mais delas, já que é intensa sua capacidade de imaginar. Porém, os momentos de contar e ler histórias devem ser divertidos também para aquele que conta e lê.

Educador que gosta e sente prazer em contar histórias transmite este mesmo sentimento de prazer e satisfação para as crianças, despertando a curiosidade de ouvir e contar muitas outras histórias sejam elas literárias ou as que representam a vida cotidiana.

Nas narrativas, o enredo, os personagens, os ambientes em que se passa a história, os sons, todos esses aspectos envolvem de tal forma que trama ganha proximidade com os fatos vivenciados no cotidiano vivido ou imaginado do ouvinte. Dessa forma, a Literatura Infantil é um elo entre o real e o imaginário, esta mediação realizada pelo contador permite à criança a fruição, o prazer e a alegria de adentrar no mundo mágico da literatura e da imaginação.

Para Real (2004) o ato de contar uma história proporciona o lúdico, o imaginário, o contato com o mundo exterior e com as coisas que o mundo proporciona, de ter direito a se divertir, de sonhar, dar risadas, movimentar-se, falar. Falar com o corpo, através da expressão, e através da linguagem oral.

A imaginação é totalmente necessária ao ser humano. A contação de história permite que a criança use e desenvolva a imaginação, que crie seu próprio mundo, o das fantasias, portanto, é preciso criar momentos em que as crianças possam alimentar sua imaginação e fantasia e assim sustentem seu imaginário de curiosidades e ideias.

De acordo com Rojas (2007, p. 22) “o lúdico é base de toda atividade 
da Educação da Infância, pois é meio de motivação para a criança, que pode dar origem a processos de aprendizagem importantes, fonte de descoberta e prazer. Ludicidade é a espontaneidade em trabalhar, fazendo a comunicação entre a fantasia, o brincar e o real".

A Proposta do Município de Cuiabá (2009) enfatiza as atividades lúdicas por meio de brincadeiras, como principal dimensão do trabalho com crianças pequenas, tomando a brincadeira como elemento orientador da prática pedagógica na Educação Infantil.

Para Andrade (2006), a atividade lúdica é uma experiência fundamental para pessoas de qualquer idade. Para as crianças pequenas, as brincadeiras e os papéis nelas desempenhados são modos largamente utilizados para descobrir e experienciar o mundo que as cerca, para se organizar e se socializar.

Desse modo, a adoção de uma prática pedagógica construída dentro de uma concepção lúdica, é referenciada e ainda indicada como um instrumento para se proporcionar uma formação integral na Educação Infantil.

Abramovich (1997, p. 27) salienta "como é importante para a formação de qualquer criança ouvir muitas, muitas histórias... Escutá-las é o início da aprendizagem para ser um leitor, e ser leitor é ter um caminho absolutamente infinito de descobertas e de compreensão do mundo...".

É preciso que se entenda que a Literatura é uma alternativa do lúdico e encanta sem estar preocupada com usos e utilidades como historicamente foi tratada. A Literatura é um recurso para ampliar imaginário e o poder de criação das crianças, um ingrediente saboroso que conduz a criança a paulatinamente conhecer o mundo, a diversidade e o seu lugar neste mundo. Por isso, sua prática em ambiente educacional infantil é de grande relevância. É comprovada a ação que contar história proporciona para a criança. Portanto, o professor tem que ser contador de história.

Assim como a contação de história envolve uma série de fatores que contribuem para seu desenvolvimento cognitivo da criança; para o contador de história, não deixa de ser diferente. O contador de história é um professor com grande bagagem cultural, um amplo vocabulário, dada a bagagem de leitura; detém memória mais rica de informações, torna-se mais seletivo e crítico e facilmente é capaz de propor um trabalho lúdico junto às crianças. É claro que temos uma visão real do mundo, mas podemos viajar por muitos lugares, além do vivido, através da Literatura. Ou seja, a leitura de histórias não encanta somente as crianças, ela encanta todas as gerações. Contar e ouvir histórias como atividades das mais antigas do homem, é uma ação que desperta prazer às pessoas de todas as idades e condições socioculturais. Nesse sentido, surge 
a seguinte pergunta: Qualquer pessoa pode contar história para criança?

$\mathrm{Na}$ Educação Infantil há sempre um educador que gosta mais de contar história, outros dizem não ter tanta habilidade. Mas uma coisa é certa! Todos nós sabemos narrar. Cada pessoa tem um jeito de contar um fato, fazer um relato, encontrando um jeito, o seu jeito de contar e recontar uma história.

Existem pessoas que são exímias contadoras de história e a fazem com naturalidade, porém como já vimos há alguns aspectos envolvidos. Exige um preparo anterior, pois estamos lidando com as narrativas guardadas em nossas lembranças ou com textos da Literatura que pedem delicadeza e cuidado com as palavras, além da preocupação do olhar para um fazer artístico, que necessita de estudo, planejamento e observação crítica.

\section{Considerações finais}

Através deste estudo e da vivência profissional verificamos que a contação de história é uma atividade frequente no dia-a-dia da Educação Infantil, porém com diferentes finalidades, ora utilizada como passa tempo, como atividade sem importância, ora para fins apenas didáticos e/ou diretivos. No entanto, sabemos que é através de um jogo simbólico de significantes e significados que a criança cria, recria e conhece o mundo que a cerca; e que este jogo simbólico se dá através das brincadeiras, que são expressão pura de comunicação, interação e emoção que levam ao desenvolvimento e aprendizagem, estes, processos indissociáveis. Assim, as práticas educativas devem estar voltadas para esta natureza da infância: a ludicidade.

Pode-se observar que são as formas de organização da sociedade e as condições de existência e de inserção da criança em cada contexto, econômico, político e cultural que vão delineando as diferentes concepções de infância e as diferentes formas de ser criança.

Vivemos numa sociedade capitalista, onde a mídia e o consumo influenciam incisivamente as crianças que se tornam cada vez mais individualistas e sem personalidade, oferecendo a elas uma gama brinquedos que em nada contribuem para o desenvolvimento da imaginação e para a socialização.

A contação de história como atividade lúdica, se constitui num caminho que leva a criança a desenvolver a imaginação, ao despertar de emoções; possibilita às crianças o desenvolvimento da linguagem, da criatividade, da reflexão, a expressão de ideias e sentimentos, enfim, possibilita interagir de forma prazerosa e significativa com o meio e com os outros.

Dessa forma, atribuída a essas finalidades a contação de história 
utilizada como instrumento educador ganha legitimidade na prática cotidiana. Considera-se também a necessidade de uma maior atenção para organização e planejamento desta atividade.

Além disso, contar história é uma atividade que dentre outras, pode desenvolver o emocional da criança, ajudá-la a se organizar, se socializar. Cabe destacar a importância da contação de história na Educação Infantil, além de vários objetivos e utilidades que lhe é dada, constitui num instrumento pedagógico prazeroso e de grande auxílio no processo de construção da aprendizagem da criança. Um ambiente interativo, socializador, rico de histórias capazes de provocar as mais incríveis sensações, emoções, ideias, expressões, é possível na Educação Infantil através da contação de histórias.

Portanto, para promover o desenvolvimento e aprendizagens infantis de forma significativa cabe-nos criar ricas e variadas situações de interação e comunicação por meio da ludicidade e da narrativa e é assim, que a contação de história ganha importância no fazer pedagógico com crianças pequenas.

\section{Referências}

ABRAMOVICH, F. Literatura Infantil: gostosuras e bobices. São Paulo: Scipione, 1997.

ANDRADE, D. B. S. F. Psicologia: desenvolvimento e aprendizagens em bebês e crianças pequenas / Daniela Barros da Silva Freire. - - Cuiabá: EdUFMT, 2006.

ARIÈS, F. História Social da criança e da família. Rio de Janeiro: Guanabara, 1986.

BAKHTIN, M. V. Estética da criação verbal. São Paulo: Martins Fontes, 1992.

BRASIL. Ministério da Educação e do Desporto. Referencial Curricular Nacional para Educação Infantil. Secretaria de Educação Fundamental. -- Brasília: MEC/SEF, 1998. v.3.

CARVALHO, B. V. de. A literatura Infantil - visão histórica e crítica. 6ạ Ed. São Paulo: Global, 1989.

CUIABÁ, Prefeitura. SME - Secretaria Municipal de Educação. Proposta Pedagógica para a Educação Infantil. Cuiabá, MT: Central de Texto, 2009.

HORN, M. G. S. Sabores, cores, sons, aromas: a organização dos espaços na Educação Infantil. Porto Alegre: Artmed, 2004. 
KRAMER, S. Infância e sociedade: o conceito de infância (Cap. I). In: Kramer, Sônia. A política do pré-escolar no Brasil: a arte do disfarce, 6ạ Ed. São Paulo: Cortez, 2001. p. 15-23.

LEARDINI, E. M. F. O contar histórias finalidades e contribuições para criança. In: O contar histórias na educação infantil: em um estudo acerca dos valores atribuídos por professores sobre a importância dessa prática para o desenvolvimento da função simbólica. Campinas: UNICAMP, 2006. $133 f$.

OLIVEIRA, A. A. de. Linguagem na Educação Infantil III. Literatura Infantil / Cuiabá: EdUFMT, 2008.

ROJAS, J. Jogos, brinquedos e brincadeiras: o lúdico e o processo de desenvolvimento infantil - Cuiabá: EdUFMT, 2007.

SISTO, C. A literatura frequenta a escola..., mas quem conta a história? In: PAROLIN, Isabel. Sou professor: a formação do professor formador / (org). Curitiba: Positivo, 2009.

VYGOTSKY, L. S. A Formação Social da Mente. São Paulo. Martins Fontes, 1991.

VYGOTSKY, L. S. Pensamento e Linguagem. São Paulo. Martins Fontes, 1994.

ZILBERMANN, R. A literatura infantil na escola. São Paulo: Global, 2003.

ZILBERMANN, R; LAJOLO, Marisa. Um Brasil para crianças. Para conhecer a Literatura Infantil: histórias, autores e textos. Rio de Janeiro: Global, 1986.

Data de recebimento: 10.09 .2019

Data de aceite: 08.07.2020 